\title{
Moisture and gamma-ray irradiation effects on the mechanical properties of carbon fibre-reinforced plastics
}

\author{
D. SEKULIĆ, D. BOŽIĆ, B. BABIĆ, J. STAŠIĆ \\ \& M. STEVANOVIĆ \\ Vinča Institute of Nuclear Sciences, P.O. Box 522, 11001 Belgrade, Serbia
}

Key words. Carbon fibre composite, epoxy resin, fractographic observation, interlaminar and in-plane shear strengths, moisture and irradiation effects.

\section{Summary}

The effects of $\gamma$-irradiation and moisture absorption on the mechanical properties of carbon fibres-epoxy resin composites were studied. The properties dominated by the matrix and fibre-matrix interface (interlaminar and in-plane shear strength) were measured at room temperature using standard tests. These tests were carried out before and after exposures to gamma irradiation and before and after immersion in water at $80^{\circ} \mathrm{C}$ during 21 days. The dosage of gamma irradiation was up to $11.7 \mathrm{MGy}$. The micrographs of surfaces fractured in performed tests were observed on a scanning electron microscope. They were analyzed with consulting the stated effects on mechanical properties and the measured values of the glass transition temperature of tested coupons before and after irradiation and immersion in water. The obtained results show that moisture and irradiation, if they act one after the other, have a significant influence on the degradation of matrix-dominated mechanical properties of the tested carbonepoxy composite.

\section{Introduction}

The increased industrial application of polymer matrix composites (PMC) involving high radiation applications (support and insulator for superconductor in fast-breeder reactors and fusion installation, coating of nuclear waste, parts of structures in nuclear power plant environment, planes and space-crafts) made the knowledge of radiation-induced aging of resin indispensable (Singh 2001).

Changes of properties of polymeric materials caused by ionizing radiation have been mainly ascribed to chemical reactions, like chain scission and/or formation of cross links (Startsev et al., 1999; Davenas et al., 2002). It has been suggested that the real situations connected with radiation effects on PMC can be far more complex, because of the high

Correspondence to: D. Sekulić. Tel: +381642770 243; fax: +381 112439 454; e-mail: pesikan.vin.bg.ac.yu sensitivity of the matrix to its environment (oxygen, water) and to the resin system composition (additives, plasticizers, processing agents etc.) (Botelho et al., 2005).

For most cases, it can be safely stated that the chain scission under irradiation is the dominant mechanism responsible for the change of properties dominated by matrix and fibre-matrix interface. The decrease of the value of composite characteristic with the irradiation is followed by the change of glass transition temperature of the matrix.

For some time, the subject of environmental degradation of carbon fibre-reinforced plastics (CFRP) has been a cause for concern, especially in aircraft structures made from such materials (Giovedi et al., 2005). As a consequence, there has been a pressing need to examine the influence of irradiation and moisture that can occur during their service (Humer et al., 1996). The aim of this paper was to evaluate the effects of $\gamma$-irradiation and moisture on the mechanical properties of carbon fibre-epoxy resin composites.

Within the scope of this paper, the effects of $\gamma$-irradiation (up to the dose of 11.7 MGy) and moisture absorption (during immersion in hot water for 3 weeks) on a carbonepoxy composite were studied. The degradation effects were estimated by measuring the interlaminar and in-plane shear strength, at room temperature, before and after immersion in water of untreated and irradiated composite plates. These effects were correlated to the measured value of glass transition temperature and interpreted in the light of SEM microfractorgaphic analysis of coupon surfaces that occurred in performed mechanical tests.

\section{Experimental}

The investigated carbon fibre-epoxy resin composite was obtained by curing the prepreg: with low-cure epoxy resin, based on tetra functional epoxy resin and novolac resins [tetraglycidyl mehylenedianiline (10-30\%), phenol formaldehyde novolac with epichlorhydrin (10-30\%), bisphenol A epoxy resin (10-30\%) and butanone (0-2\%)]. 
The hardener used is based on dicyandiamide (Dicy). The reinforcement of used prepreg is polyacrylonitrile-based unidirectional Tenax HTA $12 \mathrm{~K}$ high-strength carbon fibres of enhanced strain, manufactured by ENKA (Übach-Palenberg, Germany). Fibre area weight was $110 \mathrm{gm}^{-2}$ and the resin content was $39 \%$ by weight. The prepreg, as a product of Hexcel, was commercially available under the trade name HexPly M39/39\%/110 + 1/HS + G 616MM. It contained very little volatiles (less than $1 \%$ ). The plates were prepared by hot $\left(120^{\circ} \mathrm{C}\right)$ platen pressing $(1000 \mathrm{kPa})$ of prepreg (Sekulić et al., 2006), according to the processing conditions recommended by the supplier ( $30 \mathrm{~min}$ heating from room to the maximum temperature of $120^{\circ} \mathrm{C}$ at a heating rate of $3.5^{\circ} \mathrm{min}^{-1}, 2 \mathrm{~h}$ at $120^{\circ} \mathrm{C}$ with working pressure of $1000 \mathrm{kPa}$, and $2 \mathrm{~h}$ cooling at room temperature).

The tested laminates were made as two types of plates: unidirectional composites UDC $(0)_{\mathrm{T} 16}$ and symmetrical balanced multi-directional composites (MDC) of stacking geometry $\left( \pm 45_{4}\right)_{\mathrm{s}}$, both with 16 prepreg plies. The laminate sheets of the composites before and after irradiation and immersion in water were cut into coupons of shape and dimensions appropriate for testing.

Tested laminates were characterized by determination of (1) density, using a method of hydrostatic balance with water as a working fluid and (2) fibre content by the method of dissolution of matrix in a boiling solution of $\mathrm{H}_{2} \mathrm{SO}_{4}$ and $\mathrm{H}_{2} \mathrm{O}_{2}$. The evaluated fibre content value is $54.0 \pm 0.5 \mathrm{vol} \%$, and the density is $1510 \pm 20\left(\mathrm{kgm}^{-3}\right)$. From these two values, using densities of fibres and matrix, the evaluated void content is lower than 1 vol \%.

The laminate plates were irradiated by ${ }^{60} \mathrm{Co}$ gamma source, under a doserate of $12 \mathrm{kGyh}^{-1}$, up to the final dose of $11.7 \mathrm{MGy}$ (in the Radiation Chemistry Laboratory of Vinca Institute). Dimensions of irradiated plates were $130.0 \times 75.0 \times 2.0 \mathrm{~mm}$ for UDC $(0)_{\mathrm{T} 16}$ and $260.0 \times 150.0 \times 2.0 \mathrm{~mm}$ for $\left( \pm 45_{4}\right)_{\mathrm{s}}$ coupons.

Part of the non-irradiated and irradiated composite plates, with same dimensions as in case of irradiation, was immersed in hot water for 21 days. To speed up the moisture diffusion process, during immersion, the temperature was set at $80^{\circ} \mathrm{C}$ (Hiroyuki et al., 1994; Ogi et al., 1999; Selzer \& Friedrich 1997; Ishai et al., 1986). The water uptake in the laminate was periodically monitored during immersion of plates. After irradiations and immersions, we had four different groups of coupons: the non-irradiated non-immersed (untreated), the irradiated non-immersed (irradiated), the non-irradiated immersed (immersed) and irradiation followed by immersion.

From all these plates, the UDC $(0)_{\mathrm{T} 16}$ coupons for short beam bend tests (of dimensions $2.0 \times 10.0 \times 20.0 \mathrm{~mm}$ ) and MDC $\left( \pm 45_{4}\right)_{\mathrm{s}}$ coupons for tension tests (of dimensions $2.0 \times 25.0 \times$ $150 \mathrm{~mm})$ were cut. The $\left( \pm 45_{4}\right)_{\mathrm{s}}$ coupons were prepared for tensile tests, by attaching on all side ends of coupons the beveled tabs, made of glass fabric-reinforced polyester. The edges of the coupons were polished prior to the tests.
All mechanical tests were performed with an M 1185 INSTRON universal testing machine (Eng. Corp., High Wycombe, UK) at a temperature of $21^{\circ} \mathrm{C}$ and a relative humidity of $50 \%$. The determination of in-plane shear strength was performed by tensile test of $\left( \pm 45_{4}\right)_{s}$ coupons and the determination of interlaminar shear strength by shortbeam tree-point flexure test, both according to ISO standard documents (ISO 14129 and ISO 14130, respectively). The crosshead speed was kept constant at $1 \mathrm{~mm} \mathrm{~min}{ }^{-1}$ for all tests, and span-to-depth ratio in short-beam flexure test was 5:1. At least 8 (for $\left( \pm 45_{4}\right)_{\mathrm{s}}$ coupons) and 10 (for UDC $(0)_{\mathrm{T} 16}$ short coupons) tests were run. Statistical data analysis performed and the mean values, with standard deviations, were computed for each group of tested coupons (Figs 1 and 2).

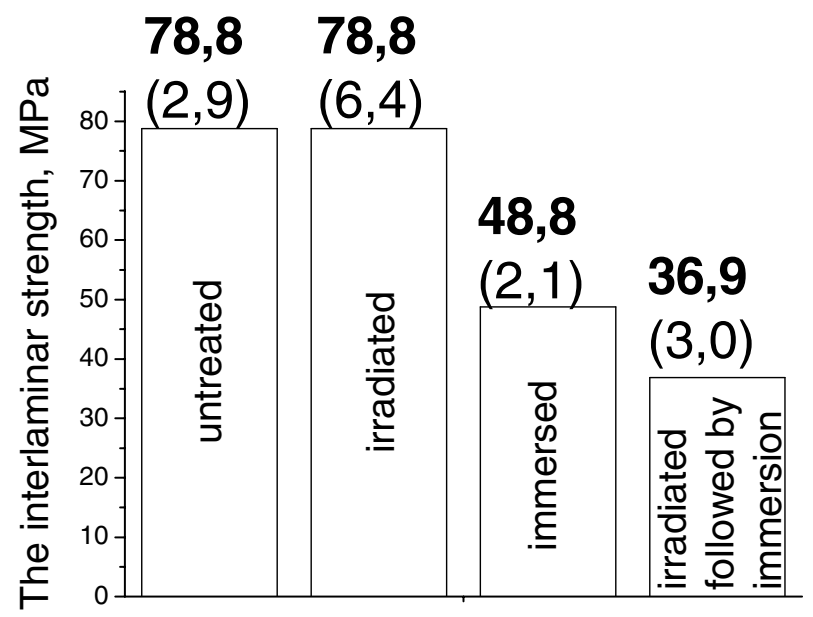

Fig. 1. The interlaminar shear strength values (with standard deviation) of four kinds of HexPly M 39 samples.

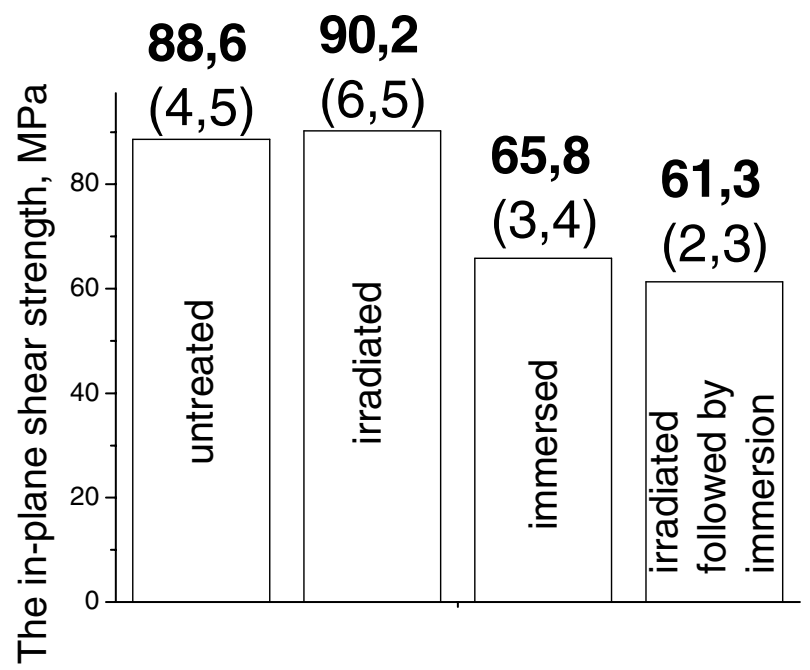

Fig. 2. The in-plane shear strength values (with standard deviation) of four kinds of HexPly M 39 samples. 


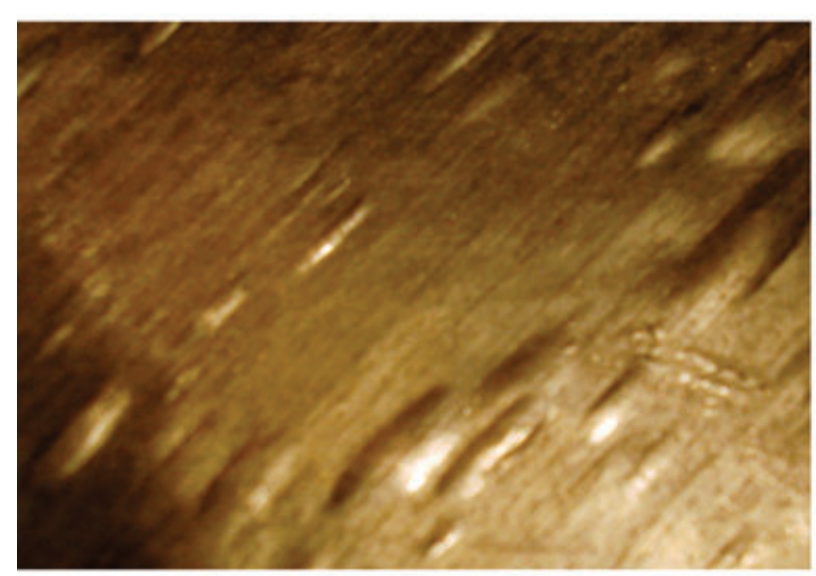

(a)

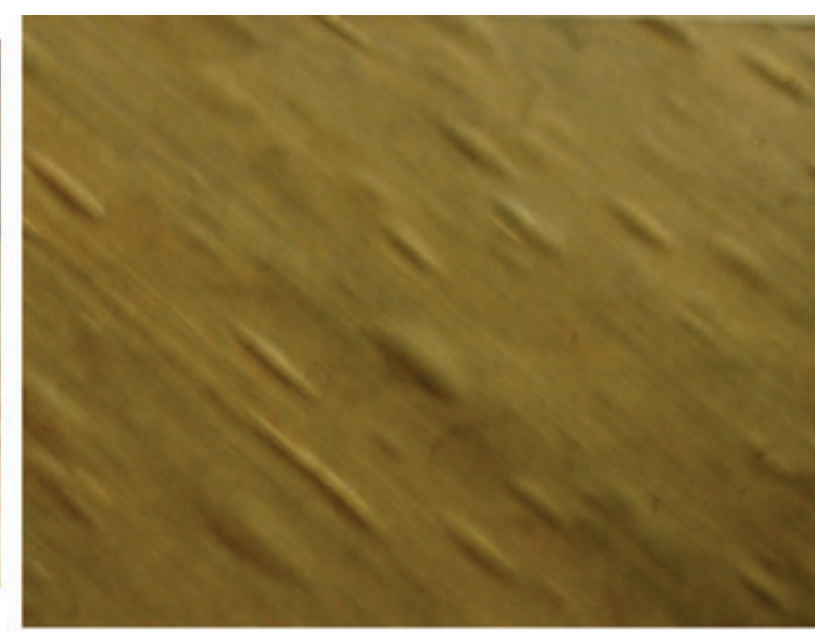

(b)

Fig. 3. The macroscopic appearance of sample surfaces: (a) immersed and (b) irradiated followed by immersion.

Dynamic mechanical analysis was performed using a Rheometrics mechanical spectrometer RMS-605 (Rheometrics, Inc., Piscataway, NJ, USA), under torsion rectangular conditions, on composite bars $(63.0 \times 12.5 \times$ $2.0 \mathrm{~mm}$ ), in the temperature range from +20 to $+200^{\circ} \mathrm{C}$. Torsion tests were conducted by heating the UDC $(0)_{\mathrm{T} 16}$ samples at a rate of $5^{\circ} \mathrm{C} \mathrm{min}-1$ (holding time was $1 \mathrm{~min}$ ) in an argon atmosphere. All the specimens had the same fibre volume fraction and the same orientation of fibres to the load $\left(0^{\circ}\right)$. The rheological properties of CFRPs are presented as mechanical spectra by following the temperature dependence of storage $\left(\mathrm{G}^{\prime}\right)$ and loss $\left(\mathrm{G}^{\prime \prime}\right)$ moduli and $\tan \delta$ peak, at a fixed frequency of $6.28 \mathrm{rads}^{-1}$. The temperature of the $\tan \delta$ maximum is taken as the glass transition temperature.

Micrographs of the fracture surfaces, failed in performed tests, observed on JEOL XL30 scanning electron microscope, working at $15-30 \mathrm{kV}$ and $20 \mathrm{~mA}$. The coupons' fractured surfaces were coated with the conductive layers of $\mathrm{Au}-\mathrm{Pd}$ alloy and carbon, by vacuum vapourization and vapour deposition, prior to SEM observations.

\section{Results and discussion}

Interlaminar (Fig. 1) and in-plane shear strength values (Fig. 2) of four kinds of tested specimens are affected in a similar way by irradiation and water uptake. The highest $\tau_{13}$ and $\tau_{12}$ values are found for untreated and irradiated coupons (their values are approximately equal within the limits of error). These results demonstrate that the irradiation to the dose of $11.7 \mathrm{MGy}$ does not have a significant effect on interlaminar and in-plane shear strength values measured at room temperature, as it was established before (Ward \& Hadlley, 1993; Abot et al., 2004). A significant descent in both $\tau_{13}$ and $\tau_{12}$ values is observed for immersed coupons, but the lowest $\tau_{13}$ and $\tau_{12}$ values are measured for irradiated followed by immersion coupons. The influence of the immersion in water is much stronger in irradiated than in untreated coupons. The relative decreases, due to immersion in water at $80^{\circ} \mathrm{C}$ for 21 days, for untreated coupons are $25.7 \%$ for $\tau_{12}$ and $38.1 \%$ for $\tau_{13}$ values, whereas for irradiated coupons, the relative decreases are $32.0 \%$ for $\tau_{12}$ and $53.2 \%$ for $\tau_{13}$ values.

The results of $\tau_{13}$ and $\tau_{12}$ measurements, at room temperature, before and after irradiation and after immersion in hot water of untreated and irradiated coupons (Figs 1 and 2) show that the absorbed moisture decreases interlaminar and in-plane shear strength values. A distinct fall in the matrix and fibre-matrix interface strength because of the effect of absorbed moisture can be ascribed to the weakening of fibrematrix interface bond and to the increase in matrix plasticity (Tenney \& Slemps 1989; Selzer et al., 1997).

All the coupons changed colour from black to green yellow after immersion, and lots of bubbles appeared only on the surface of the immersed plates (Fig. 3). It was established using a scanning electron microscope that there was no blistering throughout the thickness of the specimens. This blistering damage has a major impact on shear strength, especially on interlaminar, because the voids were on the whole surfaces, including the central plane of the specimens. It should also be taken into account that the lower $T_{\mathrm{g}}$ values of these two kinds of samples are around the temperature of immersion, which could have brought about larger damages in the resin and therefore the decrease of these two shear strengths.

The water uptake during immersion in water for irradiated coupons amounting $5.46-5.87 \%$ surpasses significantly that of untreated coupons (3.62-3.92\%) (Table 1 and Fig. 4). The higher water uptake for $\left( \pm 45_{4}\right)_{\mathrm{s}}$ coupons than for UDC $(0)_{\mathrm{T} 16}$ ones is due to the absence of interlayer in $\operatorname{UDC}(0)_{\mathrm{T} 16}$ structure and different dimensions. The established differences in water 
Table 1. The amount of water uptake in percentage with values of standard deviation for untreated and irradiated samples for both mechanical tests.

\begin{tabular}{lllll}
\hline $\begin{array}{l}\text { Immersion } \\
\text { days }\end{array}$ & $\begin{array}{l}\text { SBS test } \\
\text { Untreated }\end{array}$ & Irradiated & $\begin{array}{l}\text { Tensile test } \\
\text { Untreated }\end{array}$ & Irradiated \\
\hline 7 & $2.95 \pm 0.06$ & $3.51 \pm 0.03$ & $3.06 \pm 0.04$ & $3.66 \pm 0.05$ \\
14 & $3.40 \pm 0.04$ & $4.74 \pm 0.05$ & $3.62 \pm 0.06$ & $5.06 \pm 0.07$ \\
21 & $3.62 \pm 0.05$ & $5.46 \pm 0.07$ & $3.92 \pm 0.06$ & $5.87 \pm 0.07$ \\
\hline
\end{tabular}

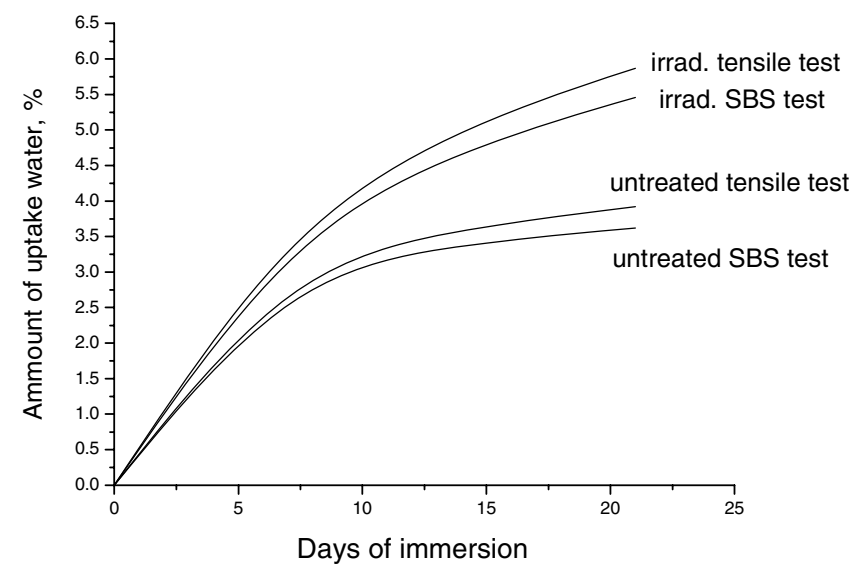

Fig. 4. Moisture-time curve for untreated and irradiated samples for SBS and tensile tests.

uptake in untreated and irradiated coupons point out that the processes in irradiated coupons during immersion are more complex than in untreated ones.

The observations of micrographs of the fracture surfaces (Figs 5 and 6) revealed that the fractures in short beam and in $\left( \pm 45_{4}\right)_{\mathrm{s}}$ coupons propagated along the fiber-matrix interface and through the matrix between the fibres for all the tested composites. The figures in matrix between the fibres, characteristic for pure interlaminar shear, are present on the fractured surface of untreated short-beam coupons (Fig. 5(a)). The micrographs of untreated and irradiated UDC $(0)_{\mathrm{T} 16}$ coupons fractured surfaces (Figs 5(a) and (b)) do not show any significant difference in the amount of matrix material adhering to the fibre surfaces. The microfractographs of immersed-and-irradiated followed by immersion coupons (Figs 6(a) and (b)) present matrix adhesion to the fibres that is less pronounced than for dry coupons (Figs 5(a) and (b)). It indicates the weakening of the fibre-matrix interface adhesion during immersion. Higher amount of naked fibres on microfractographs of immersed coupons (Figs 6(a) and (b)) imply the lowering of matrix adhesion to fibres through the interface. It can be seen from the microfractographs that the amount of resin attached to fibres in immersed samples is less than for non-immersed specimens, indicating the weakening of the adhesion during immersion.

The SEM microfractographs of fractured surfaces that appeared in tensile tests of untreated and irradiated $\left( \pm 45_{4}\right)_{\mathrm{s}}$ coupons (Figs 7(a) and (b)) are similar. However, there are no figures characteristic for shear failure in the matrix on SEM micrographs of immersed and irradiated followed by immersion surfaces emerged in failed $\left( \pm 45_{4}\right)_{s}$ coupons from tensile tests (Figs 8(a) and (b)). This fact is a consequence of plasticizing the effect of absorbed water or irradiation and absorbed water.

It is obvious from the microfractograph that the fracture in matrix is also present. The fracture through the resin is attributed to the degradation of the matrix resin, which is revealed by detection of voids in the fracture surface (Figs 7 and 8 ). The voids in the resin are formed by coalescence of the gas that evolved by the interaction between resin and $\gamma$-rays (Nishiura et al., 1990).

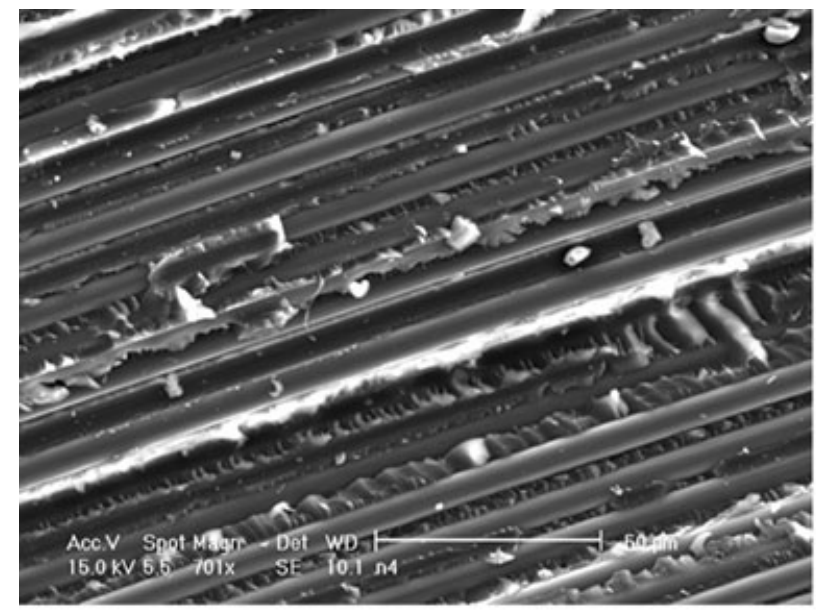

(a)

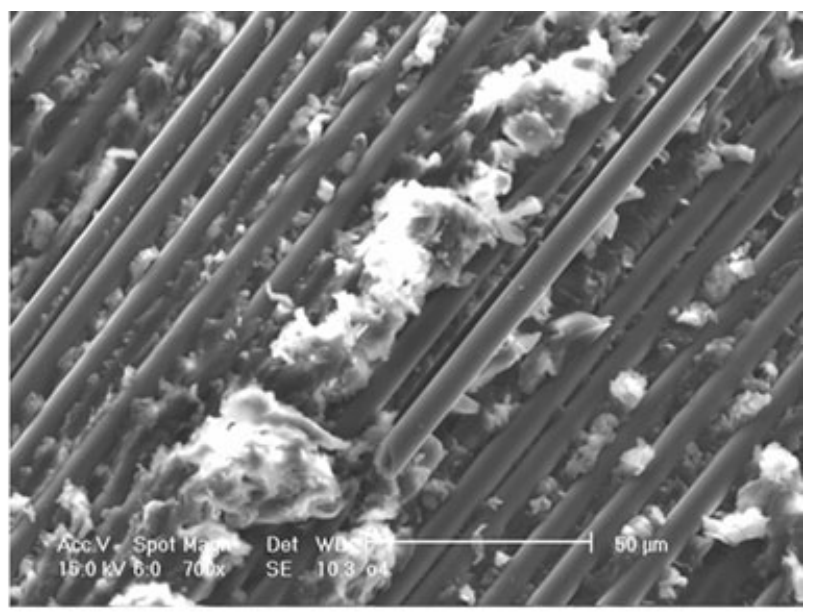

(b)

Fig. 5. SEM micrographs of surfaces fractured in short-beam flexure test of (a) untreated and (b) irradiated sample. 


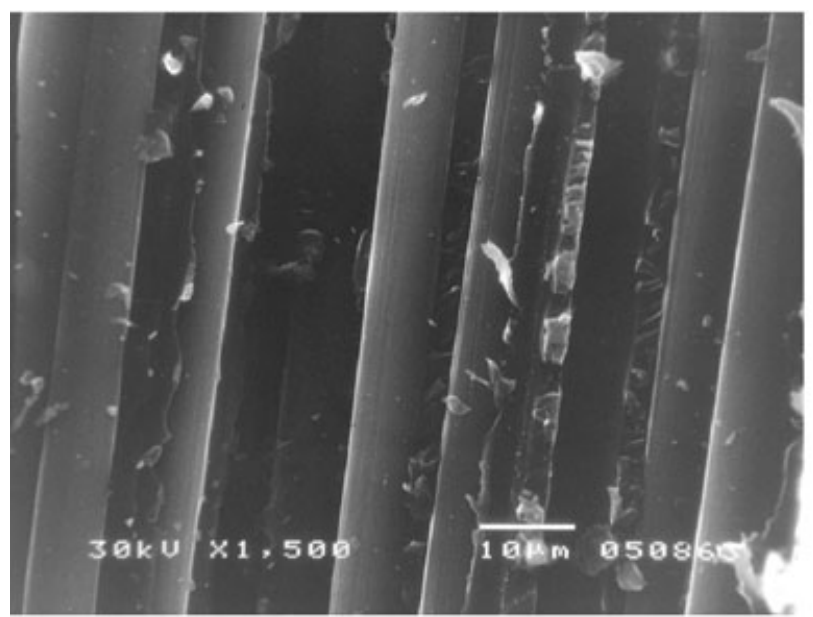

(a)

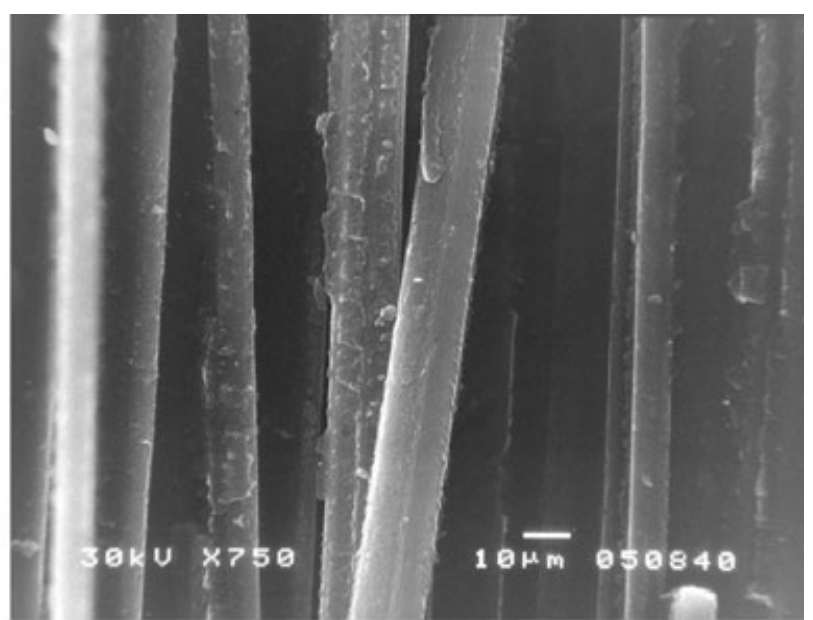

(b)

Fig. 6. SEM micrographs of surfaces fractured in short-beam flexure test of (a) immersed and (b) irradiated followed by immersion.

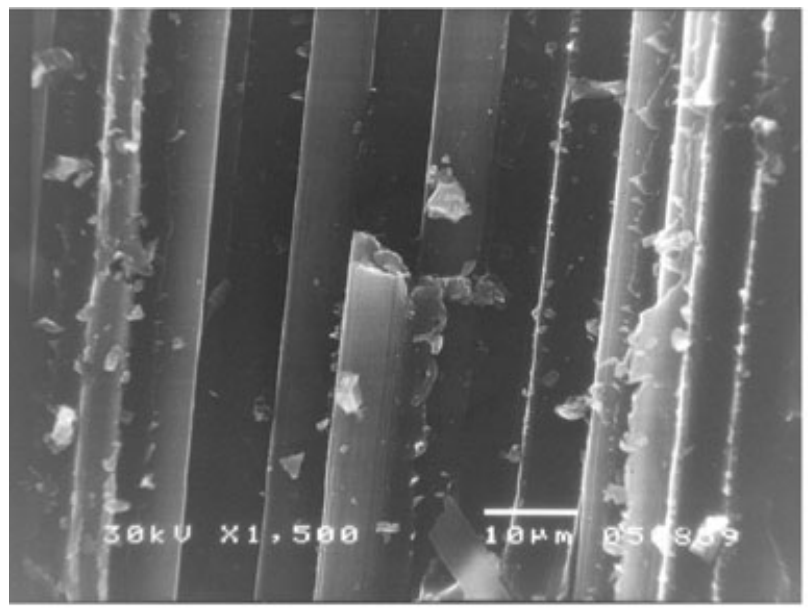

(a)

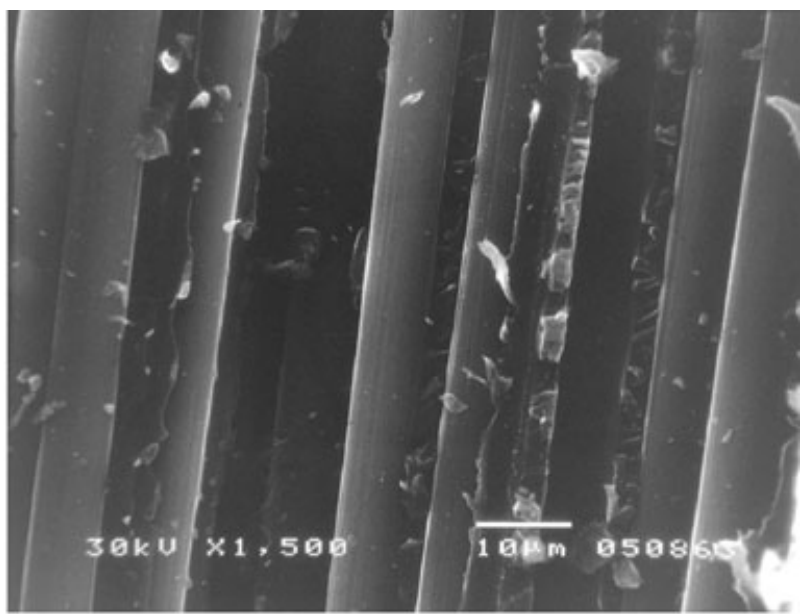

(b)

Fig. 7. SEM micrographs of surfaces fractured in tensile test of $\left( \pm 45_{4}\right)_{\mathrm{s}}$ samples for (a) untreated and (b) irradiated sample.

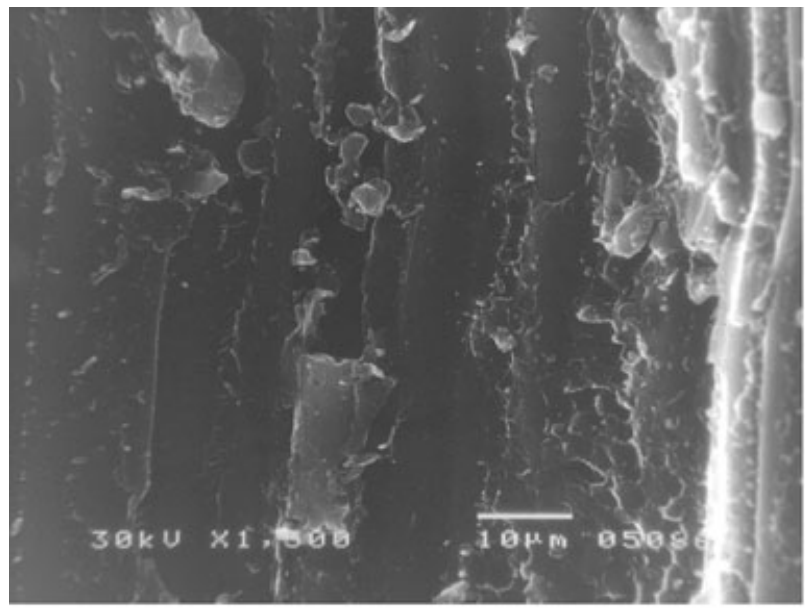

(a)

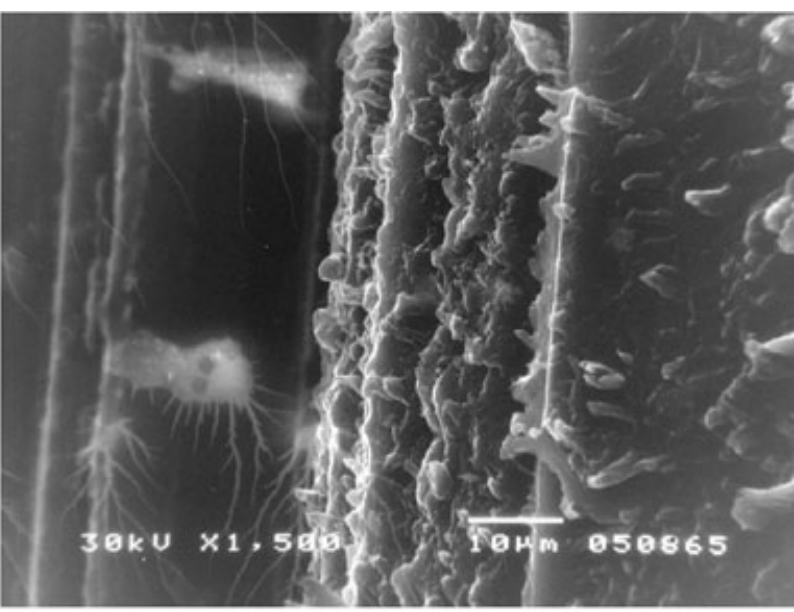

(b)

Fig. 8. SEM micrographs of surfaces fractured in tensile test of $\left( \pm 45_{4}\right)_{\mathrm{s}}$ samples for (a) immersed and (b) irradiated followed by immersion sample. 
Table 2. The glass transition temperature values, in ${ }^{\circ} \mathrm{C}$, of four different treated samples. $T_{\mathrm{g}}$ was determined as the peak in $\tan \delta$ curve obtained by DMA.

\begin{tabular}{lllll}
\hline Sample & Untreated & Irradiated & Immersed & $\begin{array}{l}\text { Irradiated followed } \\
\text { by immersion }\end{array}$ \\
\hline$T_{\mathrm{g}}$ & $121 \pm 2$ & $109 \pm 2$ & $87 \pm 1$ & $75 \pm 1$ \\
\hline
\end{tabular}

It might be presumed that along with the destruction during irradiation, polar groups, which have been formed during irradiation, disrupt the initial interchain van der Waals force and hydrogen bonds, which results in increased chain segment mobility of epoxy resin. So, the polar group acts as a plasticizer and decreases $\tau_{13}$ and $\tau_{12}$ values.

The change of the glass transition temperature $T_{\mathrm{g}}$ values (Table 2) follows the trend of $\tau_{13}$ and $\tau_{12}$ changes with immersions of the untreated and irradiated coupons (Figs 1 and 2). Sample immersion led to a large drop in $T_{\mathrm{g}}$ values, for both groups of samples (irradiated and untreated). The $T_{\mathrm{g}}$ values decrease after immersion in water is the same $\left(34^{\circ} \mathrm{C}\right)$ for both groups of samples: from 121 to $87^{\circ} \mathrm{C}$ for untreated and from 109 to $75^{\circ} \mathrm{C}$ for irradiated samples.

Dynamic-mechanical analyses confirmed that the matrix plasticization took place during water exposure. Water molecules diffuse into the material and, effectively, distribute interchain bonding established by van der Waals force and initial hydrogen bonds in the epoxy resin.

The $T_{\mathrm{g}}$ value of tested composite after irradiation to the dose of $11.7 \mathrm{MGy}$ decreases from $121^{\circ} \mathrm{C}$ to the value of $109^{\circ} \mathrm{C}$, whereas its $\tau_{13}$ and $\tau_{12}$ values, measured at room temperature, stay unchanged. This phenomenon is known in the literature (Clark et al., 1990; Buehler \& Seferis 2000). It means that the performed irradiation created latent radiation damage in matrix, as well as in the fibre-matrix interface of studied composites. This latent radiation damage could be activated by annealing of irradiated composites at temperatures near the glass transition temperature (Egusa et al., 1985; Gordic et al., 2007) or by water absorption during immersion.

The latent radiation damage has been activated during immersion of irradiated coupons in water, for 21 days, at a temperature of $80^{\circ} \mathrm{C}$, giving rise to the enhancement of the water uptake and of the degradation of properties.

\section{Conclusion}

The absorption of water during immersion at $80^{\circ} \mathrm{C}$ and exposure to gamma-ray irradiation up to the dose of 11.7 MGy induce the degradation of interlaminar and in-plane shear strength values. The degradation of these properties is exceptionally intensive during the immersion in water of previously irradiated plates. If the radiation and the humidity act in the same time, or one after the other, they degrade the epoxy matrix and the degradation product plasticizes the epoxy matrix, lowering the $\tau_{13}$ and $\tau_{12}$ values. During immersion, the water uptake for irradiated coupons surpasses significantly that for untreated coupons, whereas the depression of glass transition temperature for irradiated coupons is equal to that of untreated ones.

Experimentally obtained $T_{\mathrm{g}}$ values for immersed-andirradiated followed by immersion samples are in favour of the fact that the parts made of these materials should be applied with precaution in extreme conditions (i.e. combined influence of temperature, humidity and gamma radiation).

Applying microfractographic analysis, it was pointed out that the shear fracture in performed tests on both untreated and irradiated immersed coupons proceeded through fibrematrix interface and through the resin between fibres. The fracture through fibre-matrix interface is enhanced by weakening the interface bond to fibres because of the effect of absorbed water. The figures characteristic for shear failure in the matrix between fibres were not observed owing to the plasticizing effects of irradiation and absorbed water.

So by microfractographic analysis, we established that the dominant mechanism of the shear fracture in both performed tests on all immersed coupons is the fracture through the fibre-matrix interface and through the resin between fibres. The fracture through the resin is also present, but to a less extent. Using an SEM, we distinguish the blistering on the samples' surfaces, which has a major impact on both shear strength values.

The decrease of shear strength values after irradiation to the dose of 11.7 MGy measured at room temperature is not noticed, but the decrease of glass transition temperature of virgin composite from 121 to $109^{\circ} \mathrm{C}$ testifies that during irradiation the latent radiation damage was created. The latent radiation damage has been activated during performed immersion in water of irradiated coupons, giving rise to the enhancement of the water uptake and of the degradation of properties.

\section{Acknowledgement}

This paper was supported by the Ministry of Science and Environmental Protection, Republic of Serbia, under contract no. 142016 .

\section{References}

Abot, L., Jasmin, A., Jacobsen, A. \& Daniel, I. (2004) In-plane mechanical, thermal and viscoelastic properties of a satin fabric carbon/epoxy composite. Composites Sci. Technol. 64, 263-268.

Botelho, E., Pardini, L. \& Rezende, M. (2005) Hygrothermal effects on damping behavior of metal/glass fiber/epoxy hybrid composites. Mater. Sci. Eng. A. 399, 190-198.

Buehler, F. \& Seferis, J. (2000) Effect of reinforcement and solvent content on moisture absorption in epoxy composite materials. Composites Part A: Appl. Sci. Manuf. 31, 741-748. 
Clark, G., Saunders, D., van Blaricum, T. \& Richmond, M. (1990) Moisture absorption in graphite/epoxy laminates. Composites Sci. Technol. 39, 355-375.

Davenas, J., Stevenson, I., Celette, N., Cambon, S., Gardette, J., Rivaton, A. \& Vignoud, L. (2002) Stability of polymers under ionising radiation: the many faces of radiation interactions with polymers. Nucl. Instrum. Methods Phys. Chem. Sec. B. 191, 653-661.

Egusa, S., Kirk, M., Birther, R. \& Hagiwara, M. (1985) Annealing effects on the mechanical properties of organic composite materials irradiated with gamma rays. J. Nucl. Mater. 127, 146-153.

Gordic, M., Djordjevic, I., Sekulic, D., Petrovic, Z. \& Stevanovic, M. (2007) Delamination strain energy release rate in carbon/epoxy UDC. Mater. Sci. Forum 555, 515-521.

Giovedi, C., Machado, L., Augusto, M., Pino, E. \& Radino, P. (2005) Evaluation of the mechanical properties of carbon fiber after electron beam irradiation. Nucl. Instrum. Methods Phys. Res. B 236, 526530

Hamada, H., Morei, T., Hirano, T. \& Tanimoto, T. (1994) Weight changes of the fibre/matrix interface in GRP panels immersed in hot water. Composites Sci. Technol. 50, 373-379.

Humer, K., Spielberger, S., Weber, H., Tschegg, E. \& Gerstenberg, H. (1996) Low-temperature interlaminar shear strength of reactor irradiated glass-fibre-reinforced laminates. Cryogenics 36, 611617.

Ishai, O., Garg, A. \& Nelson, H. (1986) Hydrothermal effect on the mechanical behaviour of graphite fibre-reinforced epoxy laminates beyond initial failure. Composites 17, 23-32.

Nishiura, T., Katagiri, K., Nishijima, S. \& Okada, P. (1990) Gamma-ray irradiation effects on interlaminar tearing strength of epoxy-based FRP. J. Nucl. Mater. 174, 110-117.

Ogi, K., Kim, H., Maruyama, T. \& Takao, Y. (1999) The influence of hygrothermal conditions on the damage processes in quasi-isotropic carbon/epoxy laminates. Composites Sci. Technol. 59, 2375-2382.

Singh, A. (2001) Radiation processing of carbon fibre-reinforced advanced composites. Nucl. Instrum. Methods Phys. Res. B. 185, 50-54.

Sekulic, D., Dordević, I., Gordić, M., Burzić, Z. \& Stevanović, M. (2006) Gamma radiation effects on mechanical properties of carbon/epoxy composites. Mater. Sci. Forum 518, 549-554.

Selzer, R. \& Friedrich, K. (1997) Mechanical properties and failure behaviour of carbon fibre-reinforced polymer composites under the influence of moisture. Composites Part A: Appl. Sci. Manuf. 28(6), 595604.

Startsev, O., Krotov, A. \& Golub, P. (1999) Effect of climatic and radiation ageing on properties of VPS-7 glass fibre reinforced epoxy composite. Polym. Degrad. Stab. 63, 353-358.

Tenney, D. \& Slemps, W. (1989) The Effect of Radiation on High Technology Polymers, Chap. 9. American Chemical Society, Elsevier, Washington, DC.

Ward, I. \& Hadlley, D. (1993) An Introduction to the Mechanical Properties of Solid Polymers, Chap.7. Wiley, West Sussex. 